BMJ Open

Diabetes

Research

\& Care

\title{
Patients' with type 2 diabetes willingness to pay for insulin therapy and clinical outcomes
}

\author{
Michael D Feher, ${ }^{1,2}$ John Brazier, ${ }^{3}$ Nicolaas Schaper, ${ }^{4}$ Gabriela Vega-Hernandez, ${ }^{5}$ \\ Annie Nikolajsen, ${ }^{5}$ Mette Bøgelund ${ }^{6}$
}

To cite: Feher MD, Brazier J, Schaper N, et al. Patients' with type 2 diabetes willingness to pay for insulin therapy and clinical outcomes. BMJ Open Diabetes Research and Care 2016;4:e000192. doi:10.1136/bmjdrc-2016000192

Received 5 January 2016 Revised 25 February 2016 Accepted 29 March 2016

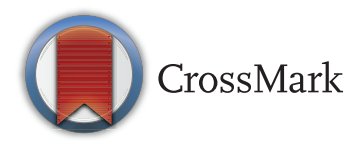

${ }^{1}$ Beta Cell Diabetes Centre, Chelsea and Westminster Hospital, London, UK ${ }^{2}$ Diabetes Therapies Evaluation Network, London, UK

${ }^{3}$ School of Health and Related Research, University of Sheffield, Sheffield, UK

${ }^{4}$ Department of Internal Medicine, CAPHRI School for Primary Care and Public Health and CARIM Institute, Maastricht University Medical Centre, Maastricht,

The Netherlands

${ }^{5}$ Novo Nordisk A/S, Soeborg, Denmark

${ }^{6}$ Incentive, Holte, Denmark

Correspondence to Dr Annie Nikolajsen; aenk@novonordisk.com

\section{ABSTRACT}

Objectives: This study assessed patient preferences, using willingness to pay as a method to measure different treatment characteristics or attributes associated with injectable insulin therapy in patients with type 2 diabetes.

Research design and methods: Adults with type 2 diabetes in 12 countries, diagnosed $>6$ months prior and receiving insulin for $>3$ months, were recruited through a representative online panel. Data were collected via online questionnaire and analyzed using a standard choice model for discrete choice experiment. Results: A total of 3758 patients from North America $(n=646)$, South America $(n=1537)$, and Europe $(n=1575)$ completed the study. Mean glycated hemoglobin $\left(\mathrm{HbA}_{1 \mathrm{c}}\right)$ levels in North America, South America, and Europe were $63 \mathrm{mmol} / \mathrm{mol}(7.9 \%)$, $75 \mathrm{mmol} / \mathrm{mol}(9.0 \%)$, and $64 \mathrm{mmol} / \mathrm{mol}(8.0 \%)$, respectively. In the three regions, monthly willingness to pay was US\$116, US\$74, and US\$92, respectively, for a $1 \%$-point decrease in $\mathrm{HbA}_{1 \mathrm{c}}$; US\$99, US\$80, and US\$104 for one less major hypoglycemic event per year; and US\$64, US\$37 and US\$60 for a $3 \mathrm{~kg}$ weight decrease. To avoid preinjection preparation of insulin, the respective values were US\$47, US\$18, and US\$37, and US\$25, US\$25, and US\$24 for one less injection per day. Among respondents on basal-only insulin who had previously tried a more intensive regimen, reasons for switching back included difficulty in handling multiple injections and risk of hypoglycemic events.

Conclusions: Reducing $\mathrm{HbA}_{1 \mathrm{c}}$, frequency of major hypoglycemic events and weight decrease were the highest valued outcomes in each region. The administrative burden of injections was also considered important.

\section{INTRODUCTION}

The economic and clinical burden of diabetes is large, both for healthcare systems, and the individuals and their families living with diabetes. ${ }^{1}$ In 2013, 382 million people worldwide were estimated to have diabetes, of which $90 \%$ had type 2 diabetes. ${ }^{1}{ }^{2}$ Globally, healthcare costs to manage diabetes and its complications totaled US\$548 billion

\section{Key messages}

- Assessing willingness to pay can be used to understand patient preference for different treatment characteristics or attributes of injectable insulin therapy for type 2 diabetes.

- Reducing glycated hemoglobin, fewer major hypoglycemic events and weight decrease were the characteristics/attributes of injectable insulin therapy valued highest by respondents.

- Respondents on basal-only insulin who had previously tried a more intensive regimen cited difficulty in handling multiple injections, risk of weight gain, and risk of hypoglycemic events as the reasons for reverting to basal-only.

in 2013 , equivalent to $11 \%$ of total worldwide health expenditure. ${ }^{1}$

Recommended glycemic goals are achieved by less than $50 \%$ of people with type 2 diabetes. ${ }^{3-6}$ Contributing to this are negative patient beliefs about the efficacy and safety of medication, and increasing complexity of therapies that may produce barriers to insulin treatments and may have an impact on medication adherence. ${ }^{48}$ Poor glycemic control has a longer term impact on clinical outcomes and associated costs, as well as short-term effects on patient symptoms and quality of life. ${ }^{9}$ As such, it is important to understand how people with type 2 diabetes perceive the management of their condition and what they will accept in terms of impact on their daily lives. This may assist treatment strategies and support patient adherence.

Patient preferences for treatments have been shown to influence adherence to treatment in type 2 diabetes, affecting glucose lowering efficacy and overall burden of disease. ${ }^{3} 10-12$ For instance, it is likely that some people with diabetes already make preference decisions on aspects, or attributes, of their treatment, for example, accepting poorer glycemic control and a higher risk of long-term complications in return for fewer episodes of hypoglycemia. ${ }^{13}$ 
One method of assessing patient preference for different treatment characteristics (attributes) is by measuring willingness to pay (WTP). WTP is defined as the amount of money an individual is willing to give up in order to procure goods or a service. ${ }^{14}{ }^{15}$ It can be derived from discrete choice experiments ${ }^{3} 16$ based on two key premises that (1) treatments can be described by their characteristics (attributes), and (2) the extent to which an individual values the treatment depends on the nature and levels of these characteristics. This is particularly relevant for people who require treatment intensification as the disease progresses, in order to maintain glycemic control. Measurement of WTP in diabetes has been demonstrated previously via discrete choice experiments in several studies. ${ }^{3} 1117$ This approach allows the relative importance of treatment attributes and the respondents' WTP to obtain or avoid attributes to be determined. ${ }^{18}$ This provides insight into which characteristics of a treatment regimen would most likely be preferred by people with type 2 diabetes. ${ }^{18}$

Data from large studies investigating WTP in type 2 diabetes are limited. The current study, using methodology similar to that used by Bogelund $e t a l^{3}$ was conducted in 12 countries across North and South America and Europe, making it the largest WTP study to date.

The study aimed to investigate patient preferences for different clinical outcomes and administration burden of insulin treatments, and to assess a measurement of respondents' WTP for several aspects of treatment or attributes related to injectable insulin therapy, with assessment of the relative importance of each attribute.

\section{METHODS}

\section{Patients}

Patients were recruited from a web-based panel derived from members recruited via telephone or online advertisements. Patients consented to participate and involvement in the study was voluntary. Respondents were required to have been diagnosed with type 2 diabetes $>6$ months and be receiving subcutaneous injection of insulin for $>3$ months but not via pump therapy. Data were collected between August 2014 and February 2015 from respondents in North America (USA and Canada), South America (Chile, Colombia, Brazil, Argentina, and Mexico) and Europe (UK, France, Italy, Germany, and the Netherlands).

\section{Design}

The study was a cross-section study design. Six focus groups were conducted to gain insights into the daily life of people with type 2 diabetes, and to identify and validate the relevant diabetes treatment attributes for inclusion in the survey. The focus groups were held in Manchester, UK $(n=4 ; n=6)$, Paris, France $(n=6 ; n=7$ plus 2 individual interviews), and Philadelphia, USA ( $\mathrm{n}=7$; $\mathrm{n}=8$ ). Participants were asked to discuss the aspects of diabetes treatment relevant to them, and to rank these aspects according to importance in their daily life. Participants also gave recommendations on how to describe each aspect to ensure relevance for people with diabetes. Finally, they were asked to assign values to specific improvements in each aspect. These findings were consolidated across the three regions and the most important features for patients with diabetes were selected as the attributes for inclusion in the online study questionnaire.

The questionnaire took approximately $15 \mathrm{~min}$ to complete and comprised six sections: (1) patient demographics; (2) attitudes of people with type 2 diabetes towards diabetes; (3) current and target $\mathrm{HbA}_{1 \mathrm{c}}$; (4) hypoglycemic events; (5) previous and current treatment and perceptions; and (6) WTP. This section was constructed around the core aspects of treatment or attributes, with a set of associated levels assigned to each attribute based on insights from the focus groups (table 1). Hypoglycemic events were defined as either 'major', if requiring assistance from another person to effect recovery; or 'minor', estimated to account for 88$98 \%$ of all events, ${ }^{19-21}$ and defined by the ability to self-treat. $^{22} 23$

The descriptive levels for each attribute were determined based on insights from the focus groups. The degree of reduction in $\mathrm{HbA}_{1 \mathrm{c}}$ and weight was assigned according to standard clinical practice.

The descriptive levels for minor and major hypoglycemic events were based on insights from the focus groups and a previous study by Evans et al. ${ }^{24}$ The descriptive levels for the other attributes (number of injections and preparation of insulin by rolling and inverting pen or vial) were determined by treatment guidelines for use of insulin. The levels for the payment attributes were based on the focus groups and results from Jendle et $a l .{ }^{16}$

From all possible combinations of attribute levels, a series of choice sets was derived using balanced, orthogonal, fractional, factorial design, generated using the Ngene discrete choice experimental design software system (developed by Choice Metric Pty Ltd) - see table 1 for an example.

This approach ensured parameter estimates were uncorrelated and could be determined independently of other attributes, and attribute levels occurred with equal frequency within the profiles, thus supporting robust results for all levels.

Each choice set presented attributes and levels for two different hypothetical diabetes treatments with payment levels documented as direct 'out of pocket' costs per month. Respondents were asked to select the preferred treatment option within each scenario, providing a hypothetical trade-off, which formed the basis of the analysis. In order to maximize the information gathered from the respondents, each respondent was randomly assigned to one of four blocks of these questions, each block consisting of nine choice sets. 
Table 1a Clinical and convenience attributes related to insulin treatment; Table 1b Typical scenario choice sets for WTP

\begin{tabular}{ll}
\hline 1a Core attributes & Levels for each attribute \\
\hline Change in $\mathrm{HbA}_{1 \mathrm{c}}$ & $1 \%$-point reduction in $\mathrm{HbA}_{1 \mathrm{c}}$ \\
Number of minor hypoglycemic events & 52 per year \\
Number of major hypoglycemic events (per 12 months) & 12 per year \\
Preparation of insulin (rolling and inverting the pen or vial) & 1 per year \\
Number of injections per day & 0 per year \\
Change in weight & Preparation of insulin \\
& 1 injection per day \\
Payment per month (out-of-pocket expense) & 4 injections per day \\
& Weight increase of $1 \mathrm{~kg}$ \\
& Remain the same weight \\
& Weight decrease of $3 \mathrm{~kg}$
\end{tabular}

\section{1b Typical WTP scenario choice sets}

\begin{tabular}{lll}
\hline & Treatment A & Treatment B \\
\hline $\mathrm{HbA}_{1 \mathrm{c}}$ levels & No change & Reduction of $1 \%$ \\
Number of minor hypos & 0 yearly & 52 yearly \\
Number of major hypos & 1 yearly & 0 yearly \\
Weight change & No change & Lose $3 \mathrm{~kg}$ \\
Preparation of insulin before injection (rolling and inverting the pen or vial) & No & Yes \\
Number of insulin injections & 1 daily injection & 4 daily injections \\
Payment per month (out-of-pocket & US\$277.50 & US\$61.05 \\
Which treatment do you prefer? & & \\
\hline
\end{tabular}

$\mathrm{HbA}_{1 \mathrm{c}}$, glycated hemoglobin; WTP, willingness to pay.

The inclusion of a test question presenting a scenario with one profile better than the others for all attributes - that is, no trade-off required-ensured respondents understood the overall concept of 'trade-off'. Respondents are likely to have different preferences for certain attributes. Therefore, in the choice set used for the test question, only the number of minor and major hypoglycemic events, and the level of payment, were different in the two treatment profiles. As per published practice, ${ }^{25}$ any respondents not selecting the superior profile were excluded. In this instance, respondents choosing the treatment with both a higher number of hypoglycemic events and a higher payment were excluded.

The questionnaire was developed in English, and translated using forward and backwards translation to the native languages of the countries included in the survey. The study was performed according to the Declaration of Helsinki w/c 14 December 2014, and anonymity of respondents was preserved in accordance with European Society for Opinion and Marketing Research, and European Pharmaceutical Market
Research Association regulations. ${ }^{26} 27$ Ethical approval was obtained from Institutional Review Board Services, Canada. Monetary values recorded in other currencies were converted to US\$ for reporting, using the exchange rates prevalent in December 2014. ${ }^{28}$

\section{Analysis}

Data were validated and checked for consistency and error before conducting the statistical analyses with the SAS analytical software package (V.9.4, SAS Institute Inc, North Carolina, USA). WTP for the different attributes was determined using a standard mixed multinomial logit model approach. The probability of choosing one option ' $\mathrm{j}$ ' from $\mathrm{n}_{\mathrm{i}}$ in a choice scenario (where there are $\mathrm{n}_{\mathrm{i}}=2$ possible options in each scenario choice set $\mathrm{C}_{\mathrm{i}}$ ) is defined by the equation ${ }^{3} 29$

$$
\mathrm{P}(\mathrm{j})=\frac{\exp \left(\chi_{\mathrm{ij}}^{\prime} \beta\right)}{\sum_{\mathrm{k} \in \mathrm{C}_{\mathrm{i}}} \exp \left(\chi_{\mathrm{ik}}^{\prime} \beta\right)}
$$

The estimated parameters $\beta$, will express preference weights for each attribute level. The WTP values for the 
attribute levels were calculated by dividing the estimated coefficients, $\beta$, for each attribute, by the coefficient of payment. The rationale underlying this approach was derived from the economic theory of demand, in which these calculated ratios are known as marginal rates of substitution. ${ }^{30}$

The linearity of the relevant attributes was then tested using a standard likelihood ratio test. This was the case for weight loss, minor hypoglycemia events and number of daily insulin injections. All these attributes exhibited linearity and so the linear function was introduced into the basic model. Interaction effects were tested according to a predefined statistical analysis plan. The results for the linear variables were then subsequently calculated per unit, for example, WTP for a weight loss of $1 \mathrm{~kg}$ or $2 \mathrm{~kg}$. Owing to the sample size required for robust analysis, WTP data were assessed by region only. The costs used in the discrete choice experimental design were presented using the currency of each country. When converting the currencies, the levels of payment were corrected for purchasing power in each country.

Since WTP data are calculated as the ratio between two stochastic variables, CIs cannot be derived directly from the parameter estimates of the conditional logit estimations. Therefore, an adapted bootstrapping methodology was applied-a method originally developed to derive the estimate of SE of an arbitrary estimator. ${ }^{31}$ The bootstrap methodology simulates the results from a random sample of the actual data available. ${ }^{32}$ Empirical research suggests that the best results are obtained when the repeated samples are the same size as the original sample and therefore the repetition is performed with replacement. ${ }^{32}$ For deriving the CIs for current WTP results, 10000 iterations were carried out. ${ }^{32}$

The WTP design and analysis were performed in accordance with the International Society for Pharmacoeconomics and Outcomes Research Good Practice for Conjoint Analysis in Health. 33 34

\section{RESULTS}

\section{Participants}

Results from 3758 respondents with type 2 diabetes were available for analysis, representing North America (USA and Canada; n=646), South America (Brazil, Chile, Colombia, Argentina, and Mexico; n=1537), and Europe (UK, Germany, the Netherlands, Italy, and France; $\mathrm{n}=1575)$.

Participants' mean age in the three regions ranged between 48.1 and 54.5 years, with the majority of respondents being male in all three regions. The mean values for duration with diabetes, duration on insulin, and BMI, are presented by region in table 2 along with sociodemographic characteristics across the three regions.

In all three regions, basal-only insulin was the most frequently used insulin regimen, followed by basal-bolus insulin. Few respondents were on bolus-only and premix- only treatment schemes. Full details of the type of insulin used are reported in table 2.

\section{Payment for insulin}

In North America, the majority of respondents paid for at least some of their medication costs; in contrast, most respondents in Europe indicated that they made no payment. In South America, approximately half paid for their medication. Full details about payment for medication are reported in table 2.

\section{$\mathrm{Hb}_{1 \mathrm{c}}$ levels}

Approximately two-thirds of respondents in each region were aware of their $\mathrm{HbA}_{1 \mathrm{c}}$ levels, with a slightly lower percentage being aware of their target $\mathrm{HbA}_{1 \mathrm{c}}$. The mean reported $\mathrm{HbA}_{1 \mathrm{c}}$ levels in North America, South America, and Europe, were $63 \mathrm{mmol} / \mathrm{mol}$ (7.9\%), $75 \mathrm{mmol} / \mathrm{mol}(9.0 \%)$ and $64 \mathrm{mmol} / \mathrm{mol} \quad(8.0 \%)$, respectively.

\section{Hypoglycemic events}

Full details pertaining to $\mathrm{HbA}_{1 \mathrm{c}}$ levels and hypoglycemic events are presented by region in table 2 .

\section{Barriers to treatment intensification}

A proportion of respondents had reverted back to basal-only insulin from an intensified regimen. In North America, most had switched back from basal-bolus insulin $(52.6 \%(41 / 78))$, followed by $38.5 \%(30 / 78)$ from premixed insulin, and $9.0 \%(7 / 78)$ from basal insulin plus a glucagon-like peptide receptor antagonist (GLP-1 RA; table 3). In South America this was 57.8\% $(115 / 199), 32.7 \%(65 / 199)$, and $9.5 \% \quad(19 / 199)$, respectively, with $48.8 \%$ (79/162), $37.7 \%(61 / 162)$, and $13.6 \%$ (22/162) in Europe.

Difficulty in handling multiple injections as well as risk of weight gain and hypoglycemia were the most frequently cited reasons for reverting back to basal-only therapy. An analysis of patients with type 2 diabetes who had reverted to basal-only insulin after previously switching to basal-bolus, premix insulin or a GLP-1 RA in combination with basal insulin, is shown in table 3 .

\section{Analysis of willingness to pay}

Results of the WTP analysis are presented in figure 1 as monetary values per month. All treatment attributes were significant predictors of choice $(\mathrm{p}<0.05)$, with high monetary values placed on efficacy and safety outcomes. In North America, respondents were willing to pay US\$116 for a $1 \%$-point decrease in $\mathrm{HbA}_{1 \mathrm{c}}(95 \%$ CI (79 to 158)). In South America, this was US\$74 (CI (54 to 97)), with US\$92 (CI (69 to 117)) in Europe. WTP for 'one less major hypoglycemic event per year' was US\$99 (95\% CI (67 to 136)), US\$80 (CI (62 to 102)), and US\$104 (CI (84 to 128)), and for 'one less minor hypoglycemic event per month', WTP was US\$34 (CI (25 to 43)), US\$21 (CI (16 to 26)), and US\$22 (CI (17 to 28)) in North America, South America, and Europe, respectively. WTP 
Table 2a Baseline characteristics of study respondents; Table 2b Glycemic control and hypoglycemia

\begin{tabular}{|c|c|c|c|c|}
\hline Category & All regions $\mathrm{n}(\%)$ & North America n (\%) & South America n (\%) & Europe n (\%) \\
\hline \multicolumn{5}{|l|}{ Table 2a } \\
\hline \multicolumn{5}{|l|}{ Clinical } \\
\hline Male/female & $58.0 \%$ & 57.7 & $54.1 \%$ & $61.9 \%$ \\
\hline Mean age (years) & 51.4 & 54.5 & 48.1 & 53.4 \\
\hline $\begin{array}{l}\text { Mean duration with diabetes } \\
\text { (years) }\end{array}$ & 10.7 & 12.4 & 9.8 & 11.0 \\
\hline Mean duration with insulin (years) & 5.7 & 6.4 & 4.8 & 6.3 \\
\hline Mean BMI(kg/m²) & 30.3 & 33.5 & 29.1 & 30.3 \\
\hline Live alone & $21.1 \%$ & $29.6 \%$ & $12.9 \%$ & $25.7 \%$ \\
\hline Have children & $74.8 \%$ & $60.5 \%$ & $83.8 \%$ & $71.8 \%$ \\
\hline Married or partnered & $68.7 \%$ & $62.7 \%$ & $68.1 \%$ & $71.6 \%$ \\
\hline College/university degree & $46.1 \%$ & $44.1 \%$ & $52.0 \%$ & $41.2 \%$ \\
\hline $\begin{array}{l}\text { In paid employment or } \\
\text { self-employed }\end{array}$ & $37.6 \%$ & $32.0 \%$ & $40.1 \%$ & $37.3 \%$ \\
\hline $\begin{array}{l}\text { Monthly household income before } \\
\text { tax }=<\text { approximately } \leq \mathrm{US} \$ 3000 \\
\text { Type of insulin used }\end{array}$ & $31.5 \%{ }^{*}$ & $32.8 \%$ & $28.0 \% *$ & $34.5 \% \dagger$ \\
\hline Basal insulin only & $1841(49.0 \%)$ & $274(42.4 \%)$ & $963(62.7 \%)$ & $604(38.4 \%)$ \\
\hline Bolus insulin only & $490(13.0 \%)$ & 59 (9.1\%) & $166(10.8 \%)$ & $265(16.8 \%)$ \\
\hline Basal and bolus insulin & $1020(27.1 \%)$ & $224(34.7 \%)$ & $274(17.8 \%)$ & $522(33.1 \%)$ \\
\hline Premixed only & $332(8.8 \%)$ & $70(10.8 \%)$ & $106(6.9 \%)$ & $156(9.9 \%)$ \\
\hline Other combination & $75(2.0 \%)$ & $19(2.9 \%)$ & $28(1.8 \%)$ & $28(1.8 \%)$ \\
\hline \multicolumn{5}{|l|}{ Payment of medication } \\
\hline Yes, I pay for all of it & $657(17.5 \%)$ & $123(19.0 \%)$ & $391(25.4 \%)$ & $143(9.1 \%)$ \\
\hline Yes, I pay for some of it & $1011(26.9 \%)$ & $335(51.9 \%)$ & $382(24.9 \%)$ & $294(18.7 \%)$ \\
\hline No, I don't pay for any of it & $2090(55.6 \%)$ & $188(29.1 \%)$ & $764(49.7 \%)$ & $1138(72.3 \%)$ \\
\hline \multicolumn{5}{|l|}{ Table 2b } \\
\hline \multicolumn{5}{|l|}{$H b A_{1 c}$} \\
\hline \multicolumn{5}{|l|}{$\mathrm{HbA}_{1 \mathrm{c}}$ and patient awareness } \\
\hline $\begin{array}{l}\text { Number of respondents } \\
\text { knowing their } \mathrm{HbA}_{1 \mathrm{c}}\end{array}$ & $2441(65.0 \%)$ & $395(61.2 \%)$ & $964(62.7 \%)$ & $1082(68.7 \%)$ \\
\hline Respondents' mean $\mathrm{HbA}_{1 \mathrm{c}}$ & $67 \mathrm{mmol} / \mathrm{mol}(8.3 \%)$ & $63 \mathrm{mmol} / \mathrm{mol}(7.9 \%)$ & $75 \mathrm{mmol} / \mathrm{mol}(9.0 \%)$ & $64 \mathrm{mmol} / \mathrm{mol}(8.0 \%)$ \\
\hline $\begin{array}{l}\text { Number of respondents who } \\
\text { are aware of target } \mathrm{HbA}_{1 \mathrm{c}}\end{array}$ & $2308(61.4 \%)$ & $392(60.7 \%)$ & 909 (59.1\%) & $1007(63.9 \%)$ \\
\hline \multicolumn{5}{|l|}{ Hypoglycemic events } \\
\hline \multicolumn{5}{|c|}{ Have respondents ever experienced a minor hypoglycemic event? } \\
\hline Yes & $2950(78.5 \%)$ & $500(77.4 \%)$ & $1202(78.3 \%)$ & $1248(79.2 \%)$ \\
\hline \multicolumn{5}{|c|}{ Frequency of minor hypoglycemic events } \\
\hline 3 times weekly & $256(8.7 \%)$ & $31(6.2 \%)$ & $112(9.3 \%)$ & $113(9.1 \%)$ \\
\hline Once weekly & $757(25.7 \%)$ & $109(21.8 \%)$ & $323(26.9 \%)$ & $325(26.0 \%)$ \\
\hline Once monthly & $805(27.3 \%)$ & $147(29.4 \%)$ & $317(26.4 \%)$ & $341(27.3 \%)$ \\
\hline Once every 3 months & $420(14.2 \%)$ & $87(17.4 \%)$ & $163(13.6 \%)$ & $170(13.6 \%)$ \\
\hline Less than once every 3 months & $712(24.1 \%)$ & $126(25.2 \%)$ & $287(23.9 \%)$ & $299(24.0 \%)$ \\
\hline Never & $710(18.9 \%)$ & $119(18.4 \%)$ & $294(19.1 \%)$ & $297(18.9 \%)$ \\
\hline Mean number of events yearly & 25.0 & 20.8 & 26.2 & 25.5 \\
\hline \multicolumn{5}{|c|}{ Have respondents ever experienced a major hypoglycemic event? } \\
\hline Yes & $929(24.7 \%)$ & $178(27.6 \%)$ & 345 (22.5\%) & $406(25.8 \%)$ \\
\hline \multicolumn{5}{|c|}{ Number of major hypoglycemic events during the past 12 months } \\
\hline 0 & $2754(73.3 \%)$ & 446 (69.0\%) & 1148 (74.7\%) & 1160 (73.7\%) \\
\hline $1-2$ & 391 (10.4\%) & 69 (10.7\%) & 137 (8.9\%) & 185 (11.7\%) \\
\hline $3-4$ & $166(4.4 \%)$ & 44 (6.8\%) & 47 (3.1\%) & 75 (4.8\%) \\
\hline $5-6$ & 75 (2.0\%) & 13 (2.0\%) & 23 (1.5\%) & 39 (2.5\%) \\
\hline $7-8$ & $24(0.6 \%)$ & $8(1.2 \%)$ & $4(0.3 \%)$ & $12(0.8 \%)$ \\
\hline $9-10$ & 49 (1.3\%) & $9(1.4 \%)$ & $21(1.4 \%)$ & $19(1.2 \%)$ \\
\hline More than 10 & $108(2.9 \%)$ & $14(2.2 \%)$ & 60 (3.9\%) & $34(2.2 \%)$ \\
\hline
\end{tabular}

*The number for South America is an estimate, since different country-specific currencies were used.

†The value for Europe is based on the \% of respondents with a monthly household income of $\leq € 1999$.

$\mathrm{BMI}$, body mass index; $\mathrm{HbA}_{1 \mathrm{c}}$, glycated hemoglobin level. 
Table 3 Patients with type 2 diabetes currently using basal insulin, previously intensified with bolus or GLP-1 RA, or premixed insulin

\begin{tabular}{|c|c|c|c|c|}
\hline \multirow[b]{2}{*}{ Patients with type 2 diabetes } & \multicolumn{4}{|l|}{ Region } \\
\hline & All regions & North America & South America & Europe \\
\hline $\begin{array}{l}\text { Total number of respondents } \\
\text { Previously added bolus to basal insulin }\end{array}$ & 439 & 78 & 199 & 162 \\
\hline $\begin{array}{l}\text { Number of patients } \\
\text { Reasons for going back to basal insulin on }\end{array}$ & $235(53.5 \%)$ & $41(52.6 \%)$ & $115(57.8 \%)$ & $79(48.8 \%)$ \\
\hline Difficult to handle multiple injections & $26.4 \%$ & $29.3 \%$ & $27.8 \%$ & $22.8 \%$ \\
\hline Risk of weight gain & $25.1 \%$ & $39.0 \%$ & $17.4 \%$ & $29.1 \%$ \\
\hline Risk of hypoglycemia events & $23.8 \%$ & $24.4 \%$ & $20.9 \%$ & $27.9 \%$ \\
\hline Difficult to calculate bolus dose & $22.1 \%$ & $14.6 \%$ & $25.2 \%$ & $21.5 \%$ \\
\hline Other reasons & $21.3 \%$ & $22.0 \%$ & $22.6 \%$ & $19.0 \%$ \\
\hline Previously added GLP-1 RA to basal insulin & & & & \\
\hline $\begin{array}{l}\text { Number of patients } \\
\text { Reasons for going back to basal insulin on }\end{array}$ & $48(10.9 \%)$ & $7(9.0 \%)$ & $19(9.5 \%)$ & $22(13.6 \%)$ \\
\hline Difficult to handle multiple injections & $29.2 \%$ & $42.9 \%$ & $31.6 \%$ & $22.7 \%$ \\
\hline Risk of hypoglycemic events & $31.3 \%$ & $0.0 \%$ & $52.6 \%$ & $22.7 \%$ \\
\hline Risk of gastrointestinal (Gl) side effects & $18.8 \%$ & $0.0 \%$ & $26.3 \%$ & $18.2 \%$ \\
\hline Other reasons & $31.3 \%$ & $57.1 \%$ & $10.5 \%$ & $40.9 \%$ \\
\hline Previously switched to premixed insulin & & & & \\
\hline $\begin{array}{l}\text { Number of patients } \\
\text { Reasons for going back to basal insulin on }\end{array}$ & $156(35.5 \%)$ & $30(38.5 \%)$ & $65(32.7 \%)$ & $61(37.7 \%)$ \\
\hline Difficult to handle multiple injections & $49.4 \%$ & $36.7 \%$ & $61.5 \%$ & $42.6 \%$ \\
\hline Risk of weight gain & $34.6 \%$ & $26.7 \%$ & $27.7 \%$ & $45.9 \%$ \\
\hline Risk of hypoglycemic events & $17.3 \%$ & $20.0 \%$ & $23.1 \%$ & $9.8 \%$ \\
\hline Other reasons & $11.5 \%$ & $23.3 \%$ & $4.6 \%$ & $13.1 \%$ \\
\hline
\end{tabular}

for a $1 \mathrm{~kg}$ weight decrease was US\$21 (CI (14 to 29)), US\$12 (CI (8 to 16), and US\$20 (CI (15 to 25)) in North America, South America, and Europe, respectively. For a
$2 \mathrm{~kg}$ weight decrease, WTP was US\$43 (CI (27 to 59)), US\$25 (CI (17 to 33)), and US\$40 (CI (31 to 50)), respectively, while for $3 \mathrm{~kg}$ decrease, WTP was US\$64 (CI
A

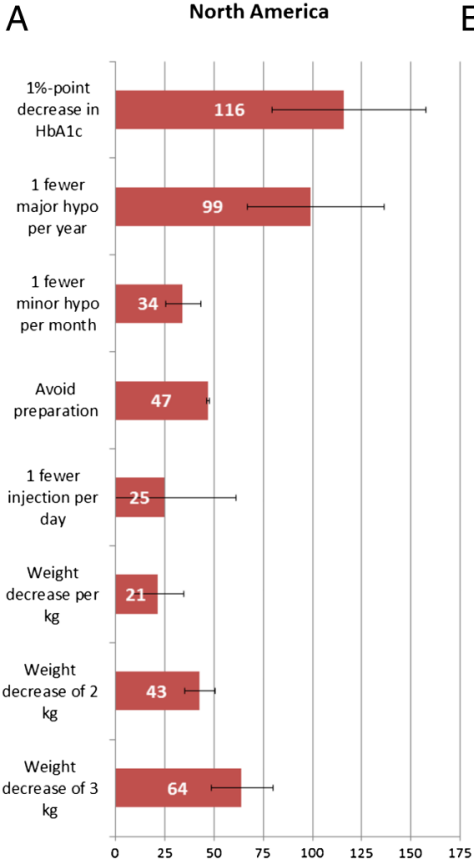

B

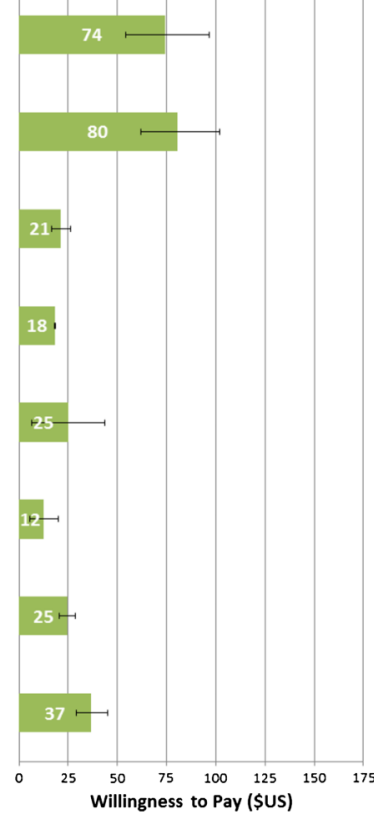

C Europe

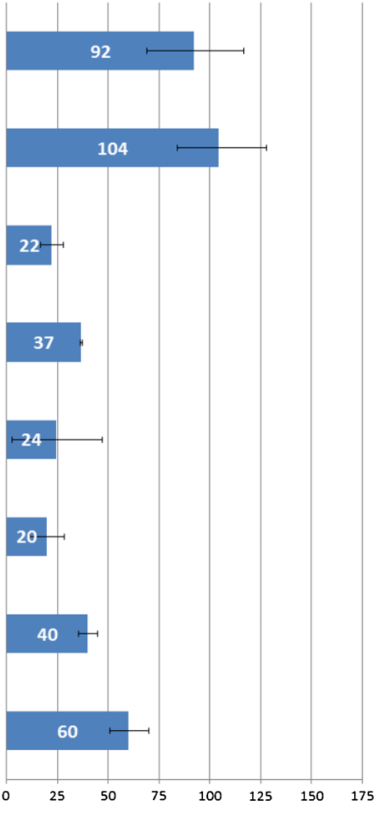

Figure 1 Willingness to pay (WTP) for clinical outcomes in separate regions: (A) (North America) (B) (South America) and (C) (Europe). $\mathrm{HbA}_{1 \mathrm{c}}$, glycated hemoglobin. 
(41 to 88$)$ ), US\$37 (CI (25 to 49)), and US\$60 (CI (46 to 75)). Additionally, in order to avoid preparation of insulin (eg, rolling and inverting the pen or vial), respondents were willing to pay US\$47 (CI (12 to 83)), US\$18 (CI $(-0.27$ to 37$)$ ), and US\$37 (CI (15 to 59$)$ ), respectively. For one less injection per day, WTP was US\$25 (CI (12 to 38$)$ ), US\$25 (CI (18 to 33)), and US\$24 (CI (16 to 33)), in North America, South America, and Europe, respectively.

An alternative way to present the outcomes of the analysis is by assessing the WTP of each attribute relative to one consistent attribute. In North America, comparing against 'reduction of minor hypoglycemic events per month by one', a 1\%-point decrease in $\mathrm{HbA}_{1 \mathrm{c}}$ was valued 3.4 times higher (US\$116 vs US\$34); one less major hypoglycemic event per year 2.9 times higher (US\$99 vs US\$34); being able to avoid preparation of insulin 1.4 times higher (US\$47 vs US\$34), and a $3 \mathrm{~kg}$ decrease in weight 1.9 times higher (US\$64 vs US\$34). Also, WTP for one less minor hypoglycemic event per month was 1.4 times more than WTP for one less injection per day (US\$34 vs US\$25).

In South America, comparing against 'reduction of minor hypoglycemic events per month by one', a 1\%-point decrease in $\mathrm{HbA}_{1 \mathrm{c}}$ was valued 3.5 times higher (US\$74 vs US\$21); one less major hypoglycemic event per year 3.8 times higher (US\$80 vs US\$21); a $3 \mathrm{~kg}$ decrease in weight 1.8 times higher (US\$37 vs US\$21), and one less injection per day 1.2 times higher (US\$25 vs US\$21). Additionally, one less minor hypoglycemic event per month was valued 1.2 times higher than being able to avoid preparation of insulin (US\$21 vs US\$18).

In Europe, comparing against 'reduction of minor hypoglycemic events per month by one', a 1\%-point decrease in $\mathrm{HbA}_{1 \mathrm{c}}$ was valued 4.2 times higher (US\$92 vs US\$22); one less major hypoglycemic event per year 4.7 times higher (US\$104 vs US\$22); being able to avoid preparation of insulin 1.7 times higher (US\$37 vs US\$22); one less injection per day 1.1 times (US\$24 vs US\$22), and a $3 \mathrm{~kg}$ decrease in weight was valued 2.7 times higher (US\$60 vs US\$22).

\section{DISCUSSION}

To the best of our knowledge, this is the largest published international study reporting willingness to pay for different treatment attributes in type 2 diabetes care and outcomes related to subcutaneous injection of insulin. The results demonstrated the relative values people with type 2 diabetes place against different attributes of treatment. The principle findings showed that treatment attributes were significant predictors of choice $(\mathrm{p}<0.05)$, with high monetary values placed on efficacy and safety outcomes. Respondents on basal-only insulin who had previously tried a more intensive regimen switched back citing the reasons as difficulty in handling multiple injections, risk of weight gain, and risk of hypoglycemic events.
Demographic split in the study population was in line with global data, with a slightly higher proportion of males. The reported frequency of hypoglycemic events is similar to previous findings of Bogelund et a $\vec{l}$ in Denmark. Additionally, the estimated annual rate of major hypoglycemic events in people with type 2 diabetes was measured by the HAT study at 2.5 events per year, while in the current study, at least one major hypoglycemic event was experienced by $22 \%$ of respondents across all regions during the past 12 months. ${ }^{55}$ Unlike previous studies, the current study presented data for both, major and minor hypoglycemic events, allowing demonstration of the relative value attributed to each. Based on the results, avoidance of major hypoglycemic events is most highly valued in Europe and South America relative to the other attributes. In North America, WTP valuation was highest for a $1 \%$-point reduction in $\mathrm{HbA}_{1 \mathrm{c}}$. Overall, nearly half of the respondents were taking basal-only insulin, accounting for the largest treatment population across all three regions. Of these, nearly a quarter of the respondents had reverted back to basal-only insulin following previous treatment intensification. Among the perceived barriers investigated, the number of daily injections, the risk of hypoglycemic events, and the risk of weight gain, were most frequently noted as reasons for discontinuing and reverting back to basal insulin. This supported the findings of the WTP analysis in that people with type 2 diabetes are keen to avoid the perceived negative outcomes of intensifying their insulin treatment. With regard to the number of daily injections, the WTP valuation for one less injection per day may appear relatively low. However, patients may potentially administer several injections on a daily basis, so considering only one less injection may not appear to be of great importance initially.

The current findings support those from country specific studies in Sweden ${ }^{16}$ and Denmark ${ }^{3}$ that include people with type 2 diabetes value improvements in treatment profile, and the resulting health and lifestyle benefits. The present results are also consistent with those from Lloyd $e t a l,{ }^{36}$ where avoidance of hypoglycemia or weight gain, and the reduction in the number of daily injections, were associated with positive WTP values relative to other attributes. For instance, WTP in North America for one less major hypoglycemic event per year, to decrease weight by $1 \mathrm{~kg}$, and to administer one less injection per day, is US\$99, US\$21 and US\$25 per month, respectively. In the US study by Hauber et $a l^{17}$ the reduction in average glucose $\left(\mathrm{HbA}_{1 \mathrm{c}}\right)$ is valued most highly by respondents, which is reflected by findings in this study, where respondents from North America were most willing to pay for a $1 \%$-point decrease in $\mathrm{HbA}_{1 \mathrm{c}}$ (US\$116 per month). This was also consistent with findings in Denmark, ${ }^{3}$ where the WTP was $€ 99$ per month for the same attribute (US\$126 per month, using December 2014 exchange rate $^{28}$ ). WTP varied across the different attributes. However, as WTP is the patients' best assessment of the value, these may differ from real 
life situations and it is likely that the relativeness between WTP values will provide a better indication of the relative importance of each attribute. For instance, in North America, 'one less minor hypoglycemic event per month' was valued low in comparison to the value of a $3 \mathrm{~kg}$ decrease in weight (US\$34 per month vs US\$64 per month). However, despite a relatively low WTP, minor hypoglycemic events are associated with a reduction in quality of life, ${ }^{37} 38$ and can interrupt and affect the ability to carry out day-to-day tasks. ${ }^{39}$ It may therefore be relevant to further analyze how patients value other clinical aspects compared to minor hypoglycemic events. In contrast, 'one less major hypoglycemic event per year' was valued high in comparison with other attributes, and valued at the same level as reducing $\mathrm{HbA}_{1 \mathrm{c}}$ by $1 \%$-point. The difference between regions in terms of the attribute that was valued the most by respondents is another area of particular interest; respondents from North America valued a 1\%-point reduction in $\mathrm{HbA}_{1 \mathrm{c}}$ the highest, compared to Europe, where a reduction in major hypoglycemic events was most valuable. Specific treatment scenarios demonstrating the applicability of the study findings (eg, the value of reducing the number of injections per day or not gaining weight) can be established. For a patient with type 2 diabetes who requires treatment intensification after failure of basal insulin in combination with oral agents, combination injectable therapy is recommended, consisting of either adding a GLP-1 RA or bolus insulin to the current therapy, or switching to premixed insulin. ${ }^{40}$ Intensifying treatment by adding bolus insulin usually requires three additional injections a day at mealtimes on top of the current basal insulin (minimum once daily), resulting in a regimen with a minimum of four injections daily. Alternatively, the patient could add a GLP-1 RA to the current basal insulin (minimum 2 daily injections) or switch to premixed insulin, which requires a total of two injections per day. According to this study, moving from a treatment with four injections per day to that with only two injections per day, was valued at US\$50 per month in North America and South America, and US\$48 per month in Europe, assuming that all other treatment aspects are the same. Another example that illustrates the applicability of the findings from this study refers to weight gain associated with insulin therapy. Although many diabetes treatments cause weight gain, some have shown to be weight neutral or even to result in weight loss. For a given treatment that provides a weight loss of $3 \mathrm{~kg}$ compared to a treatment with no weight change, all other things remaining equal, patients would value this at US\$64 per month in North America, US\$37 per month in South America, and US\$60 per month in Europe. These examples of the applicability of the value of individual treatment attributes could potentially be combined for a more in-depth assessment and exploration of the WTP for type 2 diabetes treatments that provide improvements in several of the attributes examined in this study.
There are a number of potential limitations of the study, associated with the methodology. As many patients may not regularly experience out-of-pocket expenditure for their healthcare requirements (eg, patients in Europe), the WTP estimates may differ from the value patients would pay for improvements in clinical outcomes in real-life situations. Hence the relative importance of each attribute might be a more relevant outcome of this study than the individual WTP estimates. Purchasing power is the preferred way of comparing monetary values across countries, but it is also introducing an additional uncertainty. Although the discrete choice experiments methodology is designed to restrict the potential for strategic answers from respondents, there is still potential for stated preferences within each scenario presented in the study to differ from those made by the same individual in a real-life situation. Recruitment was through online panels requiring respondents to have an email address and an adequate degree of computer literacy, which may have introduced selection bias. It is also acknowledged that, despite clear description in the questionnaire, some respondents may yet have interpreted the out-of-pocket expense as a one-off payment, rather than a monthly outlay. Furthermore, the questionnaire is self-reported, without validation of clinical characteristics by healthcare providers, resulting in potential for recall bias.

In conclusion, the present study has shown people with type 2 diabetes value improved clinical outcomes, and reduced burden of preparing and injecting insulin. Reducing $\mathrm{HbA}_{1 \mathrm{c}}$ and the number of major hypoglycemic events were attributes that generated some of the higher WTP values, but the burden associated with the preparation of dosing insulin was also considered important. Patient perceptions of the risks associated with intensifying insulin treatment may result in nonadherence and act as barriers to achieving treatment goals. Understanding patients' preferences can help to develop optimal treatment approaches for individuals with type 2 diabetes. This in turn could lead to improved clinical control through improved treatment adherence resulting in better clinical outcomes.

Acknowledgements The authors are grateful to Adelphi Values (supported by Novo Nordisk) for writing assistance.

Contributors MB completed the research and the accompanying analysis. $\mathrm{MB}, \mathrm{MDF}, \mathrm{JB}, \mathrm{GV}-\mathrm{H}$ and $\mathrm{AN}$ reviewed and edited the manuscript.

Funding This study was sponsored by Novo Nordisk.

Competing interests MDF has received financial support for research, speaker meetings and consultancy from pharmaceutical companies Merck Sharpe and Dohme, Merck, AstraZeneca, Pfizer, Sanofi, Novo Nordisk, Eli Lilly, and Boehringer Ingelheim.

Provenance and peer review Not commissioned; externally peer reviewed. Data sharing statement No additional data are available.

Open Access This is an Open Access article distributed in accordance with the Creative Commons Attribution Non Commercial (CC BY-NC 4.0) license, which permits others to distribute, remix, adapt, build upon this work noncommercially, and license their derivative works on different terms, provided 
the original work is properly cited and the use is non-commercial. See: http:// creativecommons.org/licenses/by-nc/4.0/

\section{REFERENCES}

1. International Diabetes Federation (IDF). Diabetes Atlas 2013 (updated June, 2015; cited July 2015). http://www.idf.org/sites/ default/files/EN 6E Atlas Full 0.pdf

2. Mattei J, Malik V, Wedick NM, et al. Reducing the global burden of type 2 diabetes by improving the quality of staple foods: the Global Nutrition and Epidemiologic Transition Initiative. Global Health 2015;11:23.

3. Bogelund M, Vilsboll T, Faber J, et al. Patient preferences for diabetes management among people with type 2 diabetes in Denmark - a discrete choice experiment. Curr Med Res Opin 2011;27:2175-83.

4. Garcia-Perez LE, Alvarez M, Dilla T, et al. Adherence to therapies in patients with type 2 diabetes. Diabetes Ther 2013;4:175-94.

5. Dale J, Martin S, Gadsby R. Insulin initiation in primary care for patients with type 2 diabetes: 3-year follow-up study. Prim Care Diabetes 2010;4:85-9.

6. Giugliano D, Maiorino MI, Bellastella G, et al. Efficacy of insulin analogs in achieving the hemoglobin A1c target of $<7 \%$ in type 2 diabetes: meta-analysis of randomized controlled trials. Diabetes Care 2011:34:510-17.

7. Claxton AJ, Cramer J, Pierce C. A systematic review of the associations between dose regimens and medication compliance. Clin Ther 2001;23:1296-310.

8. Peyrot M, Barnett AH, Meneghini LF, et al. Insulin adherence behaviours and barriers in the multinational Global Attitudes of Patients and Physicians in Insulin Therapy study. Diabet Med 2012;29:682-9.

9. Ridderstråle $\mathrm{M}$, Evans LM, Jensen $\mathrm{HH}$, et al. Estimating the impact of changes in $\mathrm{HbA}_{1 \mathrm{c}}$, body weight and insulin injection regimen on health related quality-of-life: a time trade off study. Health Qual Life Outcomes 2016:14:13.

10. Ahmad NS, Ramli A, Islahudin F, et al. Medication adherence in patients with type 2 diabetes mellitus treated at primary health clinics in Malaysia. Patient Prefer Adherence 2013;7:525-30.

11. Aristides $M$, Weston $A R$, FitzGerald $P$, et al. Patient preference and willingness-to-pay for Humalog Mix25 relative to Humulin 30/70: a multicountry application of a discrete choice experiment. Value Health 2004:7:442-54.

12. Gelhorn HL, Stringer SM, Brooks A, et al. Preferences for medication attributes among patients with type 2 diabetes mellitus in the UK. Diabetes Obes Metab 2013;15:802-9.

13. Leiter LA, Yale J, Chiasson J, et al. Assessment of the impact of fear of hypoglycemic episodes on glycemic and hypoglycemia management. Can J Diabetes 2005;29:186-92.

14. Le Gall-Ely M. Definition, measurement and determinants of the consumer's willingness to pay: a critical synthesis and avenues for further research. Rech et Appl en Mark 2009;24:91-112.

15. Marra CA, Frighetto L, Goodfellow AF, et al. Willingness to pay to assess patient preferences for therapy in a Canadian setting. BMC Health Serv Res 2005:5:43.

16. Jendle J, Torffvit $O$, Ridderstrale $M$, et al. Willingness to pay for health improvements associated with anti-diabetes treatments for people with type 2 diabetes. Curr Med Res Opin 2010;26: 917-23.

17. Hauber AB, Han S, Yang JC, et al. Effect of pill burden on dosing preferences, willingness to pay, and likely adherence among patients with type 2 diabetes. Patient Prefer Adherence 2013;7:937-49.

18. Veldwijk J, Lambooij MS, van Gils PF, et al. Type 2 diabetes patients' preferences and willingness to pay for lifestyle programs: a discrete choice experiment. BMC Public Health 2013;13:1099.

19. Davis RE, Morrissey M, Peters JR, et al. Impact of hypoglycaemia on quality of life and productivity in type 1 and type 2 diabetes. Curr Med Res Opin 2005;21:1477-83.
20. Donnelly LA, Morris AD, Frier BM, et al. Frequency and predictors of hypoglycaemia in type 1 and insulin-treated type 2 diabetes: a population-based study. Diabet Med 2005;22:749-55.

21. Pramming S, Thorsteinsson B, Bendtson I, et al. Symptomatic hypoglycaemia in 411 type 1 diabetic patients. Diabet Med 1991;8:217-22.

22. Committee for Medicinal Products for Human Use (CHMP). Guidelines on clinical investigation of medical products in the treatment or prevention of diabetes mellitus. 2012 (cited July 2015). http://www.ema.europa.eu/docs/en GB/document library/Scientific guideline/2012/06/WC500129256.pdf

23. Workgroup on Hypoglycemia ADA. Defining and reporting hypoglycemia in diabetes: a report from the American Diabetes Association Workgroup on Hypoglycemia. Diabetes Care 2005;28:1245-9.

24. Evans $\mathrm{M}$, Khunti $\mathrm{K}$, Mamdani $\mathrm{M}$, et al. Health-related quality of life associated with daytime and nocturnal hypoglycaemic events: a time trade-off survey in five countries. Health Qual Life Outcomes 2013;11:90.

25. Ryan M, Farrar S. Using conjoint analysis to elicit preferences for health care. BMJ 2000;320:1530-3.

26. European Society for Opinion and Marketing Research (ESOMAR). International Code on Market and Social Research. 2007 (cited July 2015). http://www.esomar.org/uploads/public/ knowledge-and-standards/codes-and-guidelines/ICCESOMAR_ Code English.pdf

27. European Pharmaceutical Market Research Association (EPHMRA). Code of conduct. 2013 (cited July 2015). http://www.ephmra.org/ user uploads/code\%20of\%20conduct\%20oct\%202013.pdf

28. Oanda. Currency Converter 2015 (cited July 2015). http://www. oanda.com/currency/converter/

29. Wooldridge JM. Econometric analysis of cross section and panel data. MIT Press, 2010:646-51.

30. Lancaster K. Consumer demand: a new approach. New York: Columbia University Press, 1971

31. Efron B, Tibshirani RJ. An introduction to the bootstrap. CRC Press, 1994.

32. Barker N. A Practical Introduction to the Bootstrap Using the SAS System 2005 (cited July 2015). http://www.lexjansen.com/phuse/ 2005/pk/pk02.pdf

33. Bridges JF, Hauber AB, Marshall D, et al. Conjoint analysis applications in health-a checklist: a report of the ISPOR Good Research Practices for Conjoint Analysis Task Force. Value Health 2011;14:403-13.

34. Johnson FR, Lancsar E, Marshall D, et al. Constructing experimental designs for discrete-choice experiments: report of the ISPOR conjoint analysis experimental design good research practices task force. Value Health 2013:16:3-13.

35. Khunti K, Alsifri S, Aronson R, et al. PO118 Self-reported hypoglycemia: a global study of 24 countries with 27,585 insulin-treated patients with diabetes: the HAT study. Diabetes Res Clin Pract 2014;106:S105-6.

36. Lloyd A, Nafees B, Barnett AH, et al. Willingness to pay for improvements in chronic long-acting insulin therapy in individuals with type 1 or type 2 diabetes mellitus. Clin Ther 2011;33:1258-67.

37. Fulcher G, Singer J, Castaneda R, et al. The psychosocial and financial impact of non-severe hypoglycemic events on people with diabetes: two international surveys. J Med Econ 2014;17:751-61.

38. Kalra S, Mukherjee JJ, Venkataraman S, et al. Hypoglycemia: the neglected complication. Indian J Endocrinol Metab 2013;17: 819-34.

39. Brod M, Christensen T, Thomsen TL, et al. The impact of non-severe hypoglycemic events on work productivity and diabetes management. Value Health 2011;14:665-71.

40. Inzucchi SE, Bergenstal RM, Buse JB, et al. Management of hyperglycaemia in type 2 diabetes, 2015: a patient-centred approach. Update to a position statement of the American Diabetes Association and the European Association for the Study of Diabetes. Diabetologia 2015;58:429-42. 